Relations industrielles

Industrial Relations

\title{
MAITRON, Jean, Le Syndicalisme révolutionnaire Paul Delesalle, 1 vol. 174 p. Editions Ouvrières, 1019. rue St-Denis, Montréal, prix: \$2.50.
}

\section{Gérard Dion}

Volume 9, numéro 3, juin 1954

URI : https://id.erudit.org/iderudit/1022886ar

DOI : https://doi.org/10.7202/1022886ar

Aller au sommaire du numéro

Éditeur(s)

Département des relations industrielles de l’Université Laval

ISSN

0034-379X (imprimé)

1703-8138 (numérique)

Découvrir la revue

Citer ce compte rendu

Dion, G. (1954). Compte rendu de [MAITRON, Jean, Le Syndicalisme révolutionnaire Paul Delesalle, 1 vol. 174 p. Editions Ouvrières, 1019. rue St-Denis, Montréal, prix: \$2.50.] Relations industrielles / Industrial Relations, 9(3), 304-304. https://doi.org/10.7202/1022886ar

Tous droits réservés (C Département des relations industrielles de l’Université Laval, 1954
Ce document est protégé par la loi sur le droit d'auteur. L'utilisation des services d’Érudit (y compris la reproduction) est assujettie à sa politique d'utilisation que vous pouvez consulter en ligne.

https://apropos.erudit.org/fr/usagers/politique-dutilisation/ 
est en faveur d'une délimitation des fonctions quand cela est possible, il démontre qu'elle peut être impossible dans la plupart des cas. Le chômage luimême ne saurait être de juridiction strict'ement fédérale. Le professeur Lamonfagne n'est ni à priori autonomiste, ni à priori centralisateur. Il est « fonctionaliste ». Si nous voulons éviter une plus grande centralisation et un changement radical de la Constitution, il faudra que chaque unité de gouvernement contribue d'une façon éclairée et dans la mesure de ses pouvoirs à la solution conjointe des problèmes qui confrontent aujourd'hui le citoyen canaàien.

L'auteur réfute ceux qui veulent placer le débat uniquement sur le plan nationaliste. Il établit que les Canadiens français se sont toujours cherché des boucs émissaires sur qui jeter le blâme de leurs insuccès. Ces boucs émissaires ont été successivement les Anglais, les Juifs et finalement le gouvernement dOttawa. Il est temps que nous envisagions 《notre question nationale 》 sous son angle positif, qui est l'enrichissement et le rayonnement de la culture française au Canada et que surtout nous prenions conscience des réalités économiques et sociales de notre pays.

Ceux qui ont franchement à coeur d'être informés sur la nature des problèmes politiques qui se posent aujourd'hui au Canada trouveront dans ce volume une abondante matière à réflexion. L'auteur lui-même en a dit que c'était une invitation à la réflexion en même temps qu'un plaidoyer pour la compréhension. Nous le recommandons spécialement aux chefs d'entreprises et de mouvements ouvriers comme étant le travail le plus important publié depuis longtemps sur la question constitutionnelle.

Yves DubÉ

MAITRON. Jean, Le Syndicalisme révolutionnaire Paul Delesalle, 1 vol. $174 \mathrm{p}$. Editions Ouvrières, 1019, rue St-Denis, Montréal, prix: $\$ 2.50$.

Cet ouvrage est la biographie d'un homme qui a incarné une forme de syndicalisme qui, en France, à une époque eut un certain retentissement: le svndicalisme révolutionnaire. Bien qu'en raison de nos principes, il nous soit im- possible d'accepter et la doctrine et la technique d'action de Paul Delesalle, le personnage, comme homme, vaut la peine d'être connu et mérite d'être apprécié pour sa sincérité. Nous conseillons d'une manière spéciale la lecture de cet ouvrage aux observateurs superficiels de la réalité syndicale. Ils y apprendront beaucoup de choses dont la moindre n'est pas de distinguer entre le véritable syndicalisme révolutionnaire et le syndicalisme que l'on rencontre en notre pays. Ils constateront encore que le syndicalisme révolutionnaire authentique rejettait toute action politique. Enfin, d'une façon indirecte, ils y verront pourquoi les circonstances historiques n'ont pas laissé aux catholiques de France d'autre issue que de créer un syndicalisme chrétien. Cet ouvrage est, en somme, un chapitre de la grande histoire du mouvement ouvrier.

\section{GÉrard Dion}

MARCY, G. RoBinot - La C.G.T., Force Ouvrière dans Revue de l'Action Populaire, janvier 1954, pp. 49-64.

Excellent article dans lequel l'auteur retrace l'évolution de la C.G.T. - F.O. depuis sa naissance jusqu'à nos jours.

PHELPS, ORME W. - Community Recognition of Union Leaders - Industrial and Labor Relations Review, Volume 7. Number 3, April 1954. po. 419-434. Issued quarterly by New York State School of Industrial and Labor Relations at Cornell University, Ithaca, New York, $\$ 5.00$ a year $-\$ 1.50$ a copy.

Le professeur Phelps enseigne les relations du travail au Claremont Men's College (U.S.A.). Il a écrit son article alors qu'il était boursier du Social Science Research Council et du Twentieth Century Fund. Est-ce que les chefs ouvriers américains possèdent un statut social en accord avec leur autorité et leur responsabilité? Telle est la question à laquelle l'auteur veut répondre. A cette fin, il examine successivement de quelle façon sont récompensés les chefs ouvriers au point de vue salaires et par rapport aux titres honorifiques qui leur sont conférés. Trouve-t-on plusieurs des 350 chefs ouvriers améri- 